\title{
Birds of the Same Feather Flock Together-Approaches to the Use of the Languages by Different Persons From Perspective of Values
}

\author{
SHEN Shuang-sheng \\ Jiangsu University, Jiangsu, China
}

\begin{abstract}
In daily communication, what one says and how to say are mainly determined by motives of the speakers. Motives are closely related to benefits and interests of the speakers concerned, they are generated from values. No one can live a life of direction and purpose without some scheme of values. And different values may generate different motives. However, values fall into different categories, and even within the values of the same tradition and culture, the big division, and conflicts exist. The study has found that this division and conflicts in values have something to do with justice and equality. Therefore, values should be taken into consideration at the study of programmatic communication.
\end{abstract}

Keywords: values, motives, justice, equality, communication

\section{Introduction}

Language is the dress of thought, and the writing reflects the writer. What a person speaks is the indication of what kind of person she or he is, reflecting speaker's value, and value is the key factor influencing the communication between different speakers. In daily communication, the reason why people violate the principles of cooperation and politeness is due to their different motives and intentions, of which the cause is the division of their values. Therefore, values should be taken into consideration on the study of communication.

\section{What the Values Are and How They Are Formed}

Here we use values in plural form for general sense, and value in singular form referring to a specific value of a person. What are values? It is not easy to give a precise definition. In general, values are indispensable for any man. They are the way in which how men exist. Chinese scholar HU (1999, p. 174) took values as the duty human should fulfill as well as a way people exist. For an individual, Value is a person's overall viewpoint and attitude towards social affairs and people around him. According to Ralph T. Eubanks and Virgil Baker (1962) (as cited in HU, 1999, p. 171), American rhetoricians, value is a viewpoint that dominates man's choice for his actions and statements. It is one of the key psychological factors for anyone, directing what a man wants to do or to say. Just as John Swift once said: “The moment you speak, you are placed”, what a person says shows what

SHEN Shuang-sheng, associate professor, School of Foreign Languages, Jiangsu University. 
kind of person he or she is, indicating what value he or she has. Therefore, people can be classified with values. That is to say: "Birds of the same feather flock together". Because value provides a criterion for a person's statements, speeches, and actions, and it is also a general judgment about such affairs relevant to oneself or others as the conducts, deeds, behaviors, words, and so on, so value is a moral standard for the basic distinguishing right from wrong as well. So is the importance of values, but how do they come into and take their roots in the thoughts of men?

Values, from a macroscopic view, are formed in the whole process of human history. Values have specific features with different nations and different cultures. They have constant elements going down from generation to generation. But to an individual, value is something a person receives and acquires from child to adult in his or her families, in schools one attends and communities in which one lives. Because an established value takes its root, and grows in the thought of men through education and influence of society, it develops as one grows. No one is born with a certain value, so there is no one in the world without values, or there is no value without men. As men live in a specific society, so values are closely related to the definite history of different countries with different norms and traditions, and in this respect, values fall into different categories. From ideological perspective to Chinese people, values can be divided into so-called socialist values and Western values. Despite the differences between this two different values, they should share their essences in common such as justice, fair, equality, honest, freedom, and democracy. Because these are the universally fundamental principles on which a reasonable society can build, maintain, and operate. However, in reality, the things are far from satisfaction. There do exist division and conflicts between different values. Any society short of these fundamental principles must be a society of deformity in which social problems and conflicts surely become difficult-to-deal-with occurrences.

\section{Root for Division and Conflicts Between Core Values}

It is natural that there should be some differences between different values of different cultures and traditions, however, values should share universally essential features such as justice, equality, democracy, freedom, legality, and so on, because men have similar feelings, affection, emotion, and needs. These features are the common ground for men to get along with. Men should live with one another in harmony and peace, but in reality, division and conflicts do exist between different values. What is the cause for division and conflicts in values? This question cannot be answered at all in the absence of conviction about the nature and destiny of man. The root for the division and conflicts results from conviction. It primarily has a link with religion. People in China and the Western world have different convictions. In the Western world, people have faith in God. But in China, the majority of people have no religious belief; they have been made to worship Man such as Confucius (KONG Zi), emperors, Marx, and historical heroes in the different phases of its history. There is a great gap between believing in God and Worshipping Man. When people have faith in God, they can be equally treated before God no matter whether they are from humble or noble origins or whether they are poor or rich. That is, all men are created equal. This conviction makes equality deeply rooted in their belief. Therefore, equality serves as one of the key principles on which their social system is built. In addition, believing in God can help people to see into their own limitedness. Their reverence to the God gives them consciously self-moral restrictions in what they do and what they say. When a crucial decision is to be made, the people concerned will weigh the 
consequences of their decisions at the very bottom of their hearts. There exists a bottom-line for their speeches and actions. With disciplines and restrictions, people have been endeavoring through endless efforts to improve themselves to reach a spiritually higher level in the whole process of their lives. In this limitedless process for perfection, people may take different ways, but the spiritual destination is the same. The equality in conviction can also give people the similar inclination in their attitudes towards social affairs. Equality, together with the rules the God told people to obey serves as a footing stone for the establishment of the shared values. But the case for Worshipping Man is quiet different. No human being is perfect, and men are born selfish in nature, men's statements and deeds are self-beneficial. Therefore, Worshipping Man indicates that at the very beginning men have taken the wrong way in their belief. Man will die, so do his words, and influential leaders' words vary from one to another. After one of the emperors and historical heroes' death, people have to shift their faith to the new ones, and these frequent shifts eventually have brought people into faithlessness. Confucius has been worshiped as a sage, a man of virtue, the sermon of whom has been strongly emphasized all through different dynasties; and the core of his sermon is "benevolence”. But "benevolence” has always been interpreted and applied according to the users' needs in history; it mainly served as a principle for governing the civilians. However, in Chinese history, none of the emperors showed any benevolence to their civilians, they ruthlessly crushed civilians' demands. Many facts have proved that nothing could be done to cruel emperors unless they were removed from the power by force, and each transformation of power was unanimously made by blood shed. What is more, Confucius also met severe criticism during MAO Ze-dong's rule in the last century. Because the practice of Worshipping Man itself has a ground that someone is born superior to others, so this belief does away with equality in people's basic conviction, the relations between people are deformed. This can be seen from the relations between emperors and their officials, relations between husbands and wives in thousand years of feudal societies in China. The followers have to obey as well as remain loyalty to their masters without any condition, otherwise, they might be hanged. Worshipping Man still manifests its bad consequence in modern society, for instance, in the last century of China, people were once classified into good ones and bad ones with the standard the privileged set, they were taught "never forget the bitterness of class oppression” (LU, 1983, p. 69), and tense relations between people were created accordingly. In accordance with this specific condition, some persons born with privileges from noble families can enjoy these privileges through their lives, including their descendants, which produce an obstacle for the fair and equality. Under this circumstance, people born superior to others have more say over social affaires, while others are made into a situation of total submitting. Worshipping Man also has a negative impact on people's way of thinking as well as their attitudes towards people and affairs around them, which would bring people into blindness to their own limits. The fact that men's conducts and deeds violated the law of the nature under the concept that "people were absolutely capable of conquering the nature” of China in the 60s in the 20th century serves a good example. In the end, Worshipping Man instead of God can bring people into a state in which moral restrictions work little and they would tell lies or even could be up to any dirty deeds or habitually make use of all kinds of lies to cover their wrong doings only for their own interests without any thought of others. Lack of equality in conviction results in the lack of basic standard for judgment, and lack of basic standard for judgment undoubtedly leads to chaos and confusions of values. In this case, division of values grows; some of the divided values may contradict with one another. In China, this can be seen from the people's different attitudes towards persons with privileges 
and powers. Some people try to associate and establish links with privileged persons or officials in order to reap benefits, while others may show opposite attitudes. This phenomenon results superficially from motives, but in reality, deeply form different values. In China, there are still a number of people adoring officials and their powers. What convictions people have matches what values they have.

People live in societies. But Human society, broadly speaking, is a society of hierarchy. It is natural that its people have different ranks and amount of wealth in accordance with their efforts and abilities. Each society needs distribution of labor among its people, so different jobs must be held by different ones with different incomes. What matters is not hierarchical system itself of the society but how the hierarchy is built and what kind of hierarchy it is. From the way how the hierarchy is established, we can know what kind of society in which people live and what kind of living condition its people have. A reasonably hierarchical society is a society in which justice, equality serve as basic criterions for social affairs, and on this ground, people are esteemed to make success by self-honesty efforts, and this commonly accepted idea can draw people together at a universally accepted values. With this value, the reasonable and fair order can be kept and the law (for the guarantee of this principle) serves as the measure and standard for one's deeds and actions. In contrary, in an unreasonable society, for the absence of this regulation but presence of inherited privileges, the privileged people can make fortune by dishonesty means, which is the destruction of the standards, and this can encourage seeking personal interests through trickery in society. This also results in unfair distribution of social wealth among its people. Short of justice and equality, in benefits or interests relevant areas, people are bound to be greatly divided in speeches and actions from different motives. Motives are direct factors relevant to interests and benefits in communication; they are the direct force giving people's tendency about what to do and what to say. Motives are generated from values. They are a psychological way of thinking as well as an inner force propelling people to move forward to his desired goal, they dominate one's speeches and actions; and they are usually stimulated by a certain needs or demands. According to Kenneth Burke (as cited in HU, 1999, p. 274), motives are indispensably associated with materials, so motives cannot be given a good explanation without the consideration of benefits or interest in communication. Material, as a kind of wealth, is pursued by people all the time. In general, people are greatly material-oriented. Values not only generate but also dominate motives. In daily life, what one needs or worth trying is determined by his or her motives. Just like one strives to get rid of illness for health and seek for food for body needs, what one needs is self-beneficial. Pursing wealth or material agrees with human's nature. However, when material or wealth is especially emphasized in a society in which economy is put at priority in all for its development, motives play an exceptionally key role in people's speeches and actions. In this case, motives can bring people into a speech and action pattern in which money or wealth is the measure of all, influencing people in their way they treat and gain wealth. Different from a reasonable society, in an unreasonable society for the short of justice and equality, there exists a case in which some people can make fortune by improper and dishonesty means, but they do all they can to cover, including the use of languages, while others may fall into victims, and these unprivileged have no choice but insist on giving the truth, appealing for justice and equality. When the gap in wealth widens to an unreasonable extent, especially large amount of wealth is controlled by minorities, then different classes of people with different wealth continually grow, along with this grows the division of people with different values in the whole society, this is because these values are closely related to their needs and demands. Under this circumstance, conflicts and 
divisions in the use of languages by people arise. This existing injustice is a strong contradiction to Confucius's "benevolence" and "righteousness".

\section{The Ground for Cooperation}

Societies vary with their systems. Each concrete social system, though equality is emphasized, has a hierarchical order in which all kinds of degrees and ranks exist; this is due to distributions of labor. Therefore, cooperation is absolutely necessary. As just said above, people are greatly material-oriented, and what one needs is self-beneficial. The relations among people are closely related with complex connections with their interests. Generally speaking, in the fields of shared interests, people are more likely to cooperate. But in the process of purse and gain of materials, some people may do something harmful to others for their own interests. So justice and equality should be the very ground for cooperation. In order to guarantee the justice and equality practiced in social life, there must be some rules for everyone to comply with. And the cooperation must be based on these publicly observed rules that no one should violate. Otherwise, he would be punished by the law. Law is the final judgment about ones' deeds. In democratic societies, every one is equal before the law. Although any one has a freedom of speech, but the speech one makes is in the range of justice and equality, within the shared values, and people have the same way of thinking with one another. In a reasonable society, the rules are strongly implemented to ensure equality and justice. Equality and justice are crucial for operation of any sound and reasonable society. Equality and justice are prerequisites for cooperation, which regulate people's deeds and actions and provide standards for people's speeches and actions. If people have this reasonable ground, though they hold different positions in hierarchical societies with different ranks and different amount of wealth, they can be united by shared interests and goals under the core values. With the ground, everyone's action can be made for all the good of the country, for the prosperity of the country can benefit all. With this shared goal and interests, the true cooperation can be achieved. A true cooperation is a cooperation in which everyone must share his part and duty in concerned social affaires without exception, and everyone's potential is brought into full play. When cooperation is required in certain areas and fields, people will ask such questions as why, how, what, and with whom. The standard for judgment comes from their shared values. If people are greatly divided and collided in their values, together with no justice and equality, people would take less responsibility for social affairs, and their selfishness and greediness will expand to extremes. This can be seen from the common occurrences in environmental pollution and making fakes in food and other products in China, among which some wrong doings have repeatedly gone beyond the bottom line of morals. With division in values, in the interests' concerned areas, people will offer conflicting answers because of different standards for judgment. Short of justice and equality, there must be short of the standard for judgment, resulting in the chaos of values. Thus the real and true cooperation is deadly difficult to reach. However, no matter what system a society belongs to, the coordination of people's actions is necessary. Usually, there are two forms of coordination of people's actions, one is compelling, the other is deciding for oneself. In compelling, men are forced to do what they are unwilling to do, they have little right to act on their own will but to obey, and in this circumstance the conflicts arise and remain difficult to be dealt with. In the long run, these conflicts will do damage to the people and their country. In the state of deciding for oneself, for one is given the right to keep the initiative in his own hands, he can act on his own free will, his actions and speeches conform to the shared values, conflicts are comparatively less and easier to be coped with. 


\section{The Use of Languages by Persons of Different Values}

Men live in societies, so the study of the languages used by men should take into consideration such factors as men's social parts, social statuses, and ranks. Sociolinguist Fishman (1972) pointed out that all kinds of variants should be taken into account for language study by saying "who speaks (or writes) what language (or what language variety) to whom and when and to what end" (p. 46). According to Austin (1962), language is the way with which people perform actions. Grice's (1975) Cooperative Principle aims at giving the rules for cooperation in people's actions as well as speeches. But in the daily communication, violation of the principle frequently occurs, for instance, indirect reply to a question or the use of rhetoric expressions such as irony, metaphor, hyperbole, and meiosis are common occurrences. The reason of the violation may vary, but one of the key reasons is that- “I do not totally agree with you on this affairs, but I do not want to offend you either”. In order to explain the limits of the Cooperative Principle, Leech (1983) put forward Politeness Principle, interpreting the reason that one violates Cooperative Principle is for the case of politeness or saving the face of participants in conversation. Of course, Politeness Principle has its drawbacks as well. Politeness is superficial. In fact, in the interests' concerned areas, politeness is usually put aside. This can be seen from business circles and all sorts of negotiations between countries in the world. From linguistic viewpoint, divisions in value work in the language people speak in communication. In a stratified society, for the short of justice and equality, people born with privileges enjoy more advantages, and they think that they are superior to others, speaking different languages from those who are born unprivileged in accordance with their social stratums, sometimes they may conceal the truth for the protection of their own interests. Others may follow by cheating or making fakes in all kinds of areas. This can trigger and produce trust crisis. In fact, this betrayal of truth in speeches and actions is also a contradiction to the demand to speak the truth, one rule of the principle of cooperation. There also appear some people who try to establish links with the privileged and have been induced to stand on the privileged side for their own sake. But there are still some people who persistently stick to justice and equality. In practice, no one cares about the principle of cooperation in a true case of communication; they care about what and how they want to say. Because no one can live a life of direction and purpose without some scheme of values, so what one says agrees to his value. Value produces motives. In daily conversation, motives play the key role and determine the direct and diction of the utterance. The words mean more than people say. The implication is really what one wants to convey in the conversation. And behind this implication are the specific motives and values. Von Humboldt (2008) once pointed out, every language embodies a unique world outlook; and the display of this world outlook is a display of certain values. Every use of speech, oral and writing, exhibits an attitude. "Your speech reveals your disposition” (Weaver, as cited in HU, 1999, p. 329), first by what you choose to say, then by amount you decide to say. Different attitudes towards the same affairs indicate different values rooted in people's minds. Weaver once said: "Language is a system of imputation, by which values and percepts are first framed in the mind and are then imputed to things” (as cited in HU, 1999, p. 330). Values determine what states societies are made into and what conditions people have in their lives, and determine what relations people have between them and what kinds of communication between them in daily life. In both English and Chinese, expressions of this can be easily found , for instance,“see eye to eye”—“志趣相投”—“have the same likes and dislikes”, or “be of similar tastes and inclinations”-“志同道合”-“have similar ideals and beliefs”, etc. 


\section{Conclusions}

This paper has been exploratory. The author does not pretend to have dealt with the topic in any depth, and perhaps the author has only stated what everyone already knows. This paper highlights the importance of values in communication, which has been ignored to some extent by Chinese pragmatic researchers. Because no one can live a life of direction and purpose without some scheme of values, so values should be taken into account at the study of the communication. The barriers in communication should be probed from divisions in values. Motives, generated from values, play dominant roles in all sorts of communications for they are closely related to benefits and materials. Men are born self-beneficial in nature, and the societies in which men live are systems of hierarchy, so justice and equality should be the basic principles for a reasonable cooperation. Without these principles, there must be big barriers between values of different cultures as well as for values within the same culture. Without the consideration of values, especially for a society of great division in values, the study of principles of cooperation and politeness, just like building a castle in the air, is short of effectiveness for explanation.

\section{References}

Austin, J. L. (1962). How to do things with words?. Oxford: The Clarendon Press.

Fishman, J. A. (1972). The sociology of language. In P. P. Giglioli (Ed.), Language and social context: Selected readings (pp. 45-58). Harmondsworth: Penguim.

Grice, H. P. (1975). Logic and conversation. In P. Cole \& J. Morgan (Eds.), Syntax and semantics: Speech acts (Vol. 3). New York: Academic Press.

HU, S. Z. (1999). New rhetoric in America. Shanghai: Shanghai foreign language education Press.

Leech, G. (1981). Semantics. Harmondsworth: Pengiun.

Leech, G. (1983). Principles of pragmatics. London: Longman.

LU, R. C. (1983). A text book for C-E translation (汉英翻译教程). Xi’an: Shan Xi People’s Press.

Von Humboldt, W. (2008). The differences in the structure of langauges and their impacts on human spiritual developments (论人 类语言结构的差异及其对人类精神发展的影响). Beijing: Commercial Press. 